\title{
Astronomical education in Mongolia
}

\author{
A. Dulmaa ${ }^{1}$, R. Tsolmon ${ }^{1}$, Ch. Lkhagvajav ${ }^{2}$, Sh. Jargalsuren ${ }^{3}$, \\ B. Bayartungalag ${ }^{1}$ and M. Zaya ${ }^{1}$ \\ ${ }^{1}$ NUM-ITC-UNESCO Remote Sensing/GIS Space Science Laboratory, \\ School of Physics and Electronics, National University of Mongolia, \\ Ikh surguuliin gudamj-1, Baga toiruu, \\ Sukhbaatar district, 210646 Ulaanbaatar, Mongolia \\ email: dulmaa@num.edu.mn \\ ${ }^{2}$ School of Physics and Electronics, \\ National University of Mongolia, \\ Ikh surguuliin gudamj-1, Baga toiruu, \\ Sukhbaatar district, 210646 Ulaanbaatar, Mongolia \\ ${ }^{3}$ Physics Department, Khovd University \\ Khovd province, Mongolia
}

\begin{abstract}
The history, current situation, education and future directions of modern Mongolian space science and astronomy is reviewed. This paper discusses recent efforts to develop astronomy education and research capacity in Mongolia with cooperation of the International Astronomical Union. Various capacity-building initiatives in space science including remote sensing in Mongolia are discussed.
\end{abstract}

Keywords. Home schooling, Mongol encyclopedia, textbooks, primary education, secondary education, high school education

\section{Introduction}

Mongolians are almost the only nation still keeping their nomadic traditions and lifestyle. Moreover, as nomads, their astronomical knowledge was transferred down from generations with ability to determine quite precisely the year, month, day and timing by celestial locations of the Sun and Moon, other planets, stars and their constellations. On par with other Asian nations, astronomy has been developing since ancient times as a science for Mongols with a deep sacral worship of the blue sky and eternal heavens.

Mongolians developed the basis for a rich astronomical and educational knowledge from ancient times. They educated the next generation by home schooling, created rich literature and special devices that draw attention to the world in astronomical education. Besides, the creations of Mongolians have a special place among the astronomical education and creations took place starting from the 3rd century such as star maps, created by Mongol astronomers and found in the 15th century. The Mongol encyclopedia of 1247 had a glossary section on astronomy. Not only the ones mentioned above, but also books and creations consisting with mentions of the mental knowledge. The culture of Mongolian astronomy is mentioned in traditional writings.

Even though Mongolians created and wrote rich foundations for astronomy for the next generation, and some of them were transferred and explored by the youths, the contents of astronomical education have not been fully established for the curricula.

Mongolia's modern educational system was set up in 1911. The contents of astronomy education was set into the curriculum of the secondary school for pupils of the 10th grade, and professional textbooks have been developed and published on this subject 
since 1950s. This was the beginning of the foundation of teaching astronomical education as an individual subject to be taught to the next generation.

Before astronomical education was taught to the pupils of the school, natural and geographical science subjects were taught and included the basic knowledge of astronomical topics. For instance: the series of one, two and three of Short book of the explanations about the Universe by Jamsranjav Tseveen written before 1940, About the Universe written by Dashdorj and Buudari, 9th planet of the outer space by Gongorjav were created as the textbook for pupils and both teachers and students were lovingly reading them, as noted in some of publications on teaching methods.

As there was not any experience of teaching astronomical education in Mongolia in the period of increase of the scope of the secondary schools in Mongolia in 1950s, the curriculum for astronomical education from Russian Schools were benchmarked and this subject was taught to the students of the 10th grade once a week for 1 hour.

Astronomy lessons were taught by graduates of the Physics and Mathematics Faculty, National University of Mongolia, established in 1942.

The astronomical educational contents were created and fully recognised between the end of 1940s and middle of 1960s. The first high school textbooks on astronomy were produced in 1965. These textbooks were renewed and the contents of the books were added in the following editions (1972, 1975 and 1980). Some ten persons went to study in graduate schools of astrophysics and received doctoral degrees in the Czech Republic and Russia, but unfortunately none of them have invested time in the education of secondary schools.

Mongolia started a transition to democracy and market economy in the 1990s. Accordingly, the educational system has undergone a drastic reform. Related to the social changes, some new subjects were introduced and included in the curriculum of public schools. One example of this change is that astronomy was included within physics. Thus, the study of astronomy was drastically reduced within the group of Physics, Natural Science and Geography, with limited number of pupils and students interested and attending.

Therefore, our deep concern and challenge is to make the study of astronomy as an individual discipline to be studied, starting in public schools, as well as systematically and in-depth at the level of universities and colleges, in order to prepare professional astronomy specialists.

\section{Goal of the research work}

To determine the current state of secondary school curriculum contents of astronomy and its development challenges in the educational system in Mongolia and some developed countries; To recommend the fundamental principles of thee conceptual framework for innovation of the educational contents of this subject.

\section{Results and discussion}

Our findings: the methods of studying astronomy have some similarities in every country, but there are two main trends:

(a) study as a part of geography, physics, Earth sciences, or other natural sciences;

(b) study as a separate individual subject.

Our recommendations: Astronomy should be studied as an individual subject in schools, starting from primary schools all the way to high schools, reflecting lessons learnt and the best practices of the global trends, with the following proposed contents: 
Table 1. Basic contents for IV-V grade students (aged 10-12)

\begin{tabular}{ll}
\hline & Natural Sciences $\quad$ IV-V grades \\
\hline 1 Astronomical observations & What do you see in the sky at night? \\
& Big Dipper (Great seven gods), Polaris (compass star) \\
& How many stars are there in the sky? \\
& Stories related to the stars in Mongolia and other countries \\
\hline 2 Stars and galaxies & Some properties of the stars \\
\hline & Place of thousands suns \\
& Is it possible to live on a star? \\
& Far away from the stars \\
\hline 3 The Sun and the solar sys- & The Sun, Moon and planets \\
\hline tem & The shape and physical size of the Sun and its distance \\
& Motion of the Sun and the Moon \\
& The influence of the Sun \\
& The Earth \\
& Mercury, Venus, Mars, Jupiter, Saturn \\
& Can anyone live on other planets?
\end{tabular}

- Primary education. Children, from their early ages, asks a wide variety of questions about the stars, the sky, and what they were and how they relate to each other and how they are studied and so on. This is required to educate these children from their early ages based on their interest and matching to their age difference and teach them what the sky and stars are and how they are related to each other and how the human beings and the outer space relate to each other. This is possible to improve this knowledge from their primary classes. Within the frame of this subject, children are able to acquire knowledge using all possible resources such as observing the sky and the stars. These practices can be carried out by themselves, and the subjects should include all possible resources in it. Also the children not only study textbooks and observe the sky, but also they can be observe the climate changes and natural phenomena and many other aspects (see Table 1).

- Secondary education. The contents have been designed so that all children in the 7-9th grades get all the aspects of physics and astronomy. Students connect these understanding with the knowledge of natural sciences, natural phenomena and after this they will continually study the subjects in the upper classes and have a basic preparation for real-life subjects. Topics include the basic understanding of astronomy in the 7-9th grades (see Table 2).

- High school education. Astronomy should be studied deeply within the framework of physics and natural sciences (see Table 3).

In order to develop astronomy and space science in Mongolia we look forward to many more years of cooperation with the IAU and other educational organisations.

\section{Conclusions}

In Mongolia, the high school curricula must be connected to natural science subjects and give more knowledge about the universe. The basics of astronomy should be studied step by step while in the secondary education this subject should be studied more deeply so that the students will be acculturated to the knowledge of astronomy and the universe. 
Table 2. Basic contents for VII-IX grade students (aged 13-15)

\begin{tabular}{ll}
\hline & Basic astronomy VII-IX grades \\
\hline 1 Astronomical observations & Methods for observing the motion of astronomical objects \\
& Constellations which can be seen and their main brightest stars \\
& To identify the planets and note the differences with stars \\
& The celestial sphere \\
& Physical place of the planets \\
& The Zodiacal constellations and their brightest stars \\
\hline 2 Stars and galaxies & Properties of the stars \\
\hline & Star \\
& Colours of the stars, radii and temperatures \\
& Binary stars and star clusters \\
& Our Galaxy \\
\hline The Sun and the solar sys- & The solar system \\
& Composition of the solar system \\
& Planets and their appearance \\
& Lunar phases and the axis of the Earth \\
& Rotation of the Earth \\
& The orbital motion of the Earth \\
Motion of the planets \\
Asteroids and comets \\
The Copernican system
\end{tabular}

Table 3. Basic contents for X-XII grade students (aged 16-18)

\begin{tabular}{|c|c|}
\hline \multicolumn{2}{|c|}{ Natural Sciences $\quad$ IV-V grades } \\
\hline 1 Astronomical observations & Star maps \\
\hline & $\begin{array}{l}\text { Location of constellations on the Mongolian sky } \\
\text { Determine } 28 \text { constellations on the Moon's orbit } \\
\text { Calendar, specifications and how they were invented } \\
\text { Decades, years, days and } 24 \text { hours }\end{array}$ \\
\hline 2 Stars and galaxies & Magnitudes of stars \\
\hline & $\begin{array}{l}\text { The luminosity of stars and their absolute magnitudes } \\
\text { Spectra of stars, colours and temperatures } \\
\text { Special properties of the stars } \\
\text { The origin of the stars and their evolution }\end{array}$ \\
\hline $\begin{array}{l}3 \text { The Sun and the solar sys- } \\
\text { tem }\end{array}$ & The origin of the solar system \\
\hline & $\begin{array}{l}\text { Properties of the planets } \\
\text { Formation of the planets } \\
\text { Energy resources of the Sun and the stars } \\
\text { The slow evolution of the Sun and the stars } \\
\text { Structure of galaxies and their formation } \\
\text { Applications of remote sensing } \\
\text { Principles of Geographic Information Systems }\end{array}$ \\
\hline
\end{tabular}




\section{References}

Baasanjav, D. 2008, Астрономийи цаглабар- 2009 Astronomical Calendar - 2009 (Ulaanbaatar: Tod khevlel press)

Batmunkh, D. 2006, IAU Special Session 5, Astronomy for the Developing World, J.B. Hearnshaw and P. Martinez (eds) (Cambridge: Cambridge University Press), p. 167

Burbaa, B. et al. 2003, Физик болпвсролыи стандарт / Physics Educational Standard (Ulaanbaatar: Ministry of Education, Culture and Science, National center on standardization and metrology press)

Burmaa, B., Ganbat, M., \& Maabazar, R. 1999, Физик-2/Physics 2 Textbook (Ulaanbaatar: Soyombo Printing Press)

Byamba, G. 2001, Физик-Одон орон / Physics and Astronomy-10, (Ulaanbaatar: Ulaanbaatar press)

Dulmaa, A., \& Bayartungalag, B. 2007, in Proceedings of the Second National Workshop on Application of Remote Sensing/GIS for Mongolian Environment (Ulaanbaatar: NUM Press), p. 92

Ganbat, M., Byrmaa, B., Batbold, D., Dulmaa, A., Chuluunbaatar, G., \& Munkhsaikhan, Ya. 2007, Физик-9/Physics-9 Textbook (Ulaanbaatar: Soyombo Printing Press)

Hearnshaw, J. et al. 2007, IAU Transactions, Vol. 26A, Reports on Astronomy 2002-2005, O. Engvold (ed.) (Cambridge: Cambridge University Press), p. 387

Isobe, S. 1999, Teaching of Astronomy in Asian-Pacific Region, Bulletin No. 15 (Tokyo: National Astronomical Observatory of Japan Press)

Levitan, Y. 1989, Баачуудад одон гарийи тухай / Stars and planets for children, translated into Mongol, (Moscow: Raduga Inc.)

Maabazar, R. 1994, Дуну сургуулийи сурагчдаар хийлж астрономийи ажиглалтын агуулга арга зуй / Contents of astronomy observations and methods made by schools pupils, (Ulaanbaatar: Ulaanbaatar Press)

Ninjbadgar, S. 1965, Астрономи/Astronomy/Astronomy, (Ulaanbaatar: Science Academy press)

Shagdar, Sh. 2000, Монголын боловсролын туухзн товчоон / Educational history of Mongolia (Ulaanbaatar: Bambi Press) 